\title{
PENGARUH PERENCANAAN PAJAK TERHADAP MANAJEMEN LABA
}

\section{Husnul Khotimah}

UIN Syarif Hidayatullah Jakarta

\section{ABSTRACT}

Profit is an assertion of management that needs to be proven its quality. However, reported earnings do not necessarily reflect the real situation, because it allows the case of earnings management. There are various tools that can be done to explain earnings management, including in terms of tax planning. Thus, this study aims to examine the relationship between tax planning with earnings management.

The study uses data companies listed on the Indonesian Stock Exchange in 2009 until 2011. Sample included 84 companies consisting of 49 companies in 2010 and 35 companies in 2011. Tax planning include the effective tax rate and deferred tax expense while earnings management is measured by the current discretionary accruals.

The results of empirical testing using e-views 6 shows that positive tax planning proxy significantly related to earnings management is the effective tax rate. While the deferred tax expense not found a significant relationship. In general, the results showed that the tax planning has effect on the amount of current discretionary accruals.

Keywords: Tax planning, earnings management, effective tax rates, deferred tax expense and current discretionary accruals.

\section{PENDAHULUAN}

Laba merupakan asersi manajemen yang perlu dibuktikan kualitasnya. Kualitas laba menjadi pusat perhatian bagi investor, kreditor, pembuat kebijakan akuntansi dan pemerintah (Sugianto dan Siagian, 2007). Informasi laba dalam laporan keuangan pada umumnya penting, khususnya bagi mereka yang menggunakan laporan keuangan untuk tujuan kontrak dan pengambilan keputusan investasi (Sugianto dan Siagian, 2007). Tetapi, menurut teori keagenan yang dinyatakan pertama kali oleh Jensen dan Meckling (1976), konflik kepentingan terjadi diantara pemilik (investor) dengan agen (manajemen) untuk memaksimalkan utilitas masing-masing. Sehingga akan memunculkan tanda tanya mengenai laba yang dilaporkan. Maka, kualitas laba suatu perusahaan sangat diperhatikan oleh principal. Namun, penyusunan laporan keuangan berbasis akrual, sebagaimana yang diatur dalam PSAK 1 (IAI, 2009) dilakukan oleh manajemen, sehingga memungkinkan manajemen bertindak sesuai dengan kepentingannya atau dikenal dengan istilah manajemen laba.

Penelitian mengenai manajemen laba banyak menggunakan proksi dan variabel yang berbeda-beda, diantaranya dengan mempertimbangkan tarif pajak efektif (Comprix et al. 2012; Lin et al. 2012; Cook et al. 2008), pajak tangguhan (Philips et al. 2003; Chia-Ling et al. 2004; Yulianti, 2004) dan akrual (Philips et al. 2003). Penelitian tarif pajak biasanya mempertimbangkan perubahan tarif pajak dalam menjelaskan manajemen laba, seperti Tax Reform Act (TRA) tahun 1986, sedangkan pajak tangguhan lebih menekankan pada peranan beban pajak tangguhan tersebut dalam pengaruhnya terhadap manajemen laba. Maka, 
insentif pajak memainkan peranan penting dalam perilaku manajemen laba perusahaan (Lin et al. 2012).

Philips et al. (2003) menemukan bahwa beban pajak tangguhan lebih berguna secara inkremental dalam mendeteksi manajemen laba dibanding total akrual dan abnormal akrual. Tetapi, penelitian ini bertentangan dengan Yulianti (2004) yang memberikan bukti terdapat pengaruh tidak signifikan antara beban pajak tangguhan dan manajemen laba. Proksi perencanaan pajak lain yang sering diteliti adalah tarif pajak efektif (Effective Tax Rate, ETR). Tarif pajak efektif ini merupakan pembagian beban pajak kini atau beban pajak dengan laba sebelum pajak. Dalam penelitian di Cina, Lin et al. (2012) menemukan hubungan yang signifikan antara marginal tax rate dengan manajemen laba yang diproksikan dengan discretionary accrual. Sama halnya dengan Yin dan Cheng (2004), penelitian ini mempertimbangkan perubahan tarif pajak di Cina. Sedangkan Comprix et al. (2012) yang mengacu pada penelitian Dhaliwal et al. (DGM, 2004) mengungkapkan bahwa selisih tarif pajak efektif kuartil 3 dengan kuartil 4 merupakan indikasi terjadinya manajemen laba.

Penelitian ini merupakan pengembangan penelitian yang dilakukan oleh Yin dan Cheng (2004) yang mengungkapkan terdapat hubungan yang negatif dan signifikan antara perencanaan pajak dengan manajemen laba yang diukur dengan discretionary accrual. Namun, tidak seperti Yin dan Cheng (2004) yang mempertimbangkan terjadinya perubahan tarif pajak sehingga dapat memicu perencanaan pajak dan manajemen laba, dalam penelitian ini proksi perencanaan pajak yang digunakan adalah tarif pajak efektif (effectif tax rate, ETR) seperti yang dilakukan oleh Lin et al. (2012), karena tidak mempertimbangkan penurunan tarif pajak. Kemudian dimasukkan proksi beban pajak tangguhan yang dalam penelitian Philips et al. (2003) ditemukan hubungan yang signifikan dengan manajemen laba. Leverage dan size ditambahkan sebagai variabel kontrol karena sudah banyak penelitian yang menyatakan terdapat hubungan antara leverage dan size terhadap manajemen laba. Pengukuran manajemen laba menggunakan current discretionary accrual karena sebagaimana yang diungkapkan oleh Guenther (1994), penelitian pengenai pajak penghasilan lebih sesuai jika menggunakan current discretionary accrual. Insentif pajak memainkan peranan penting dalam perilaku manajemen laba perusahaan. Banyak penelitian telah menguji laporan keuangan perusahaan berkaitan dengan Tax Reform Act (TRA) 1986 di U.S dan telah melaporkan bukti yang cukup bahwa pajak memicu manajemen laba. Namun hanya sedikit penelitian yang mengeksplorasi manajemen laba di pasar negara berkembang (Lin et al, 2012). Maka, penelitian ini berupaya memberikan bukti empiris mengenai pengaruh perencanaan pajak yang diukur dengan dua proksi yang sering digunakan, yaitu tarif pajak efektif dan beban pajak tangguhan dalam pasar di Indonesia. 


\section{METODOLOGI PENELITIAN}

\subsection{Sampel Penelitian}

Sampel dalam penelitian ini diambil dari data laporan keuangan perusahaan yang terdaftar dalam Bursa Efek Indonesia tahun 2009 sampai 2011. Metode pemilihan sampel menggunakan teknik purposive sampling, dengan kriteria:

- Terdaftar dalam Bursa Efek Indonesia.

- Memiliki item-item yang diperlukan untuk pengujian

- Tidak termasuk dalam perusahaan yang penghasilannya bersifat final, seperti jasa konstruksi, industri keuangan dan WP dengan ketentuan khusus dan pencadangan.

- Tidak mengalami kerugian akuntansi.

\subsection{Model Penelitian}

Pengujian hipotesis dilakukan menggunakan model regresi linier berganda dengan persamaan regresi sebagai berikut:

$\mathrm{DCA}_{\mathrm{t}}=\alpha_{0}+\alpha_{1} \mathrm{ETR}_{\mathrm{t}}+\alpha_{2} \mathrm{DTE}_{\mathrm{t}}+\mathrm{b}_{2} \mathrm{LEV}_{\mathrm{t}}+\mathrm{b}_{3} \mathrm{LNAT}_{\mathrm{t}}+\varepsilon \mathrm{t}$.

Dimana:

DCA $_{\mathrm{t}}=$ discretionary current accruals tahun $\mathrm{t}$, diukur menurut perhitungan yang dilakukan oleh Yin dan Cheng (2004).

ETR $_{\mathrm{t}}=$ tarif pajak efektif (ETR) dihitung dengan membagi beban pajak kini dengan laba sebelum pajak.

DTE $_{t}=\left(\mathrm{DTE} / \mathrm{TA}_{\mathrm{t}-1}\right)$, kenaikan atau penurunan aktiva pajak tangguhan atau liabilitas pajak tangguhan yang tercermin dalam beban pajak tangguhan tahun $t$ diskala (dibagi) dengan total aset tahun lalu.

$\mathrm{LEV}_{\mathrm{t}}=$ total hutang dibagi total aset awal tahun

$\mathrm{LNAT}_{\mathrm{t}}=$ natural logaritma total aset

Pengukuran discretionary current accrual menggunakan perhitungan yang dilakukan oleh Yin dan Cheng (2004), yaitu:

a. Mencari Current Acrual

$\mathrm{CACC}_{\mathrm{t}}=\left(\Delta \mathrm{CA}_{\mathrm{t}}-\Delta \mathrm{Cash}_{\mathrm{t}}\right)-\left(\Delta \mathrm{CL}_{\mathrm{t}}-\Delta \mathrm{STD}_{\mathrm{t}}-\Delta \mathrm{ITP}_{\mathrm{t}}\right)$

Di mana:

$\mathrm{CACC}_{\mathrm{t}}=$ current accrual

$\Delta C A_{t}=$ perubahan current asset

$\mathrm{h}_{\mathrm{t}} \quad=$ perubahan kas dan setara kas

$\Delta C \mathrm{Ci}_{\mathrm{t}}=$ perubahan current liabilities

$\Delta \mathrm{STD}_{\mathrm{t}}=$ perubahan debt yang termasuk current liabilities

$\Delta \mathrm{ITP}_{\mathrm{t}}=$ hutang pajak penghasilan 
b. Meregresikan nilai current acrual dari perhitungan (2) dengan pembagian antara perubahan penjualan $(\triangle \mathrm{SALE})$ dengan lagged total asset $\left(\mathrm{A}_{\mathrm{t}-1}\right)$ :

$\mathrm{CACC}_{\mathrm{t}} / \mathrm{A}_{\mathrm{t}-1}=\beta_{1}\left(\Delta \mathrm{SALE}_{\mathrm{t}} / \mathrm{A}_{\mathrm{t}-1}\right)$.

c. Mencari nilai discretionary acrual:

$\mathrm{DA}_{\mathrm{t}}=\left(\mathrm{CACCt} / \mathrm{A}_{\mathrm{t}-1}\right)-\mathrm{b}_{1}\left(\Delta \mathrm{SALE}_{\mathrm{t}} / \mathrm{A}_{\mathrm{t}-1}\right)$

\section{Kerangka Penelitian}

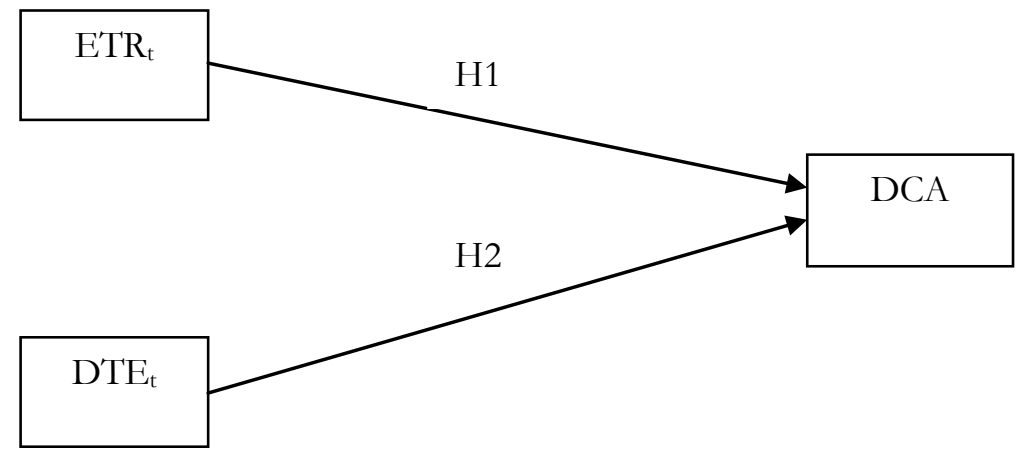

\section{ANALISIS DAN PEMBAHASAN}

\subsection{Statistik Deskriptif}

Tabel 1

\begin{tabular}{|l|r|r|r|r|r|}
\hline Variabel & DCA & ETR & DTE & LEV & LNAT \\
\hline Mean & 0.0001732 & 0.2140192 & 0.0049907 & 0.5084645 & 27.7487771 \\
\hline Median & 0.0012299 & 0.2229154 & 0.0027998 & 0.5111450 & 27.8441484 \\
\hline Maximum & 0.2345390 & 0.5904209 & 0.0254954 & 0.9054003 & 32.2337728 \\
\hline Minimum & -0.2204808 & 0.0581286 & 0.0001259 & 0.1232497 & 22.2118658 \\
\hline N & 84 & 84 & 84 & 84 & 84 \\
\hline
\end{tabular}

Sumber: diolah menggunakan microsoft excell dengan confidence level 95\%.

Sampel penelitian terdiri dari dari 455 perusahaan di tahun 2010 dan 2011. Kemudian setelah dilakukan pengeluaran sampel yang tidak termasuk kriteria yang disebutkan di atas, terpilih sampel yang terdiri dari 95 perusahaan, 52 perusahaan di tahun 2010 dan 43 perusahaan di tahun 2011. Tetapi, peneliti menghilangkan 3 perusahaan di tahun 2010 dan 8 perusahaan di tahun 2011 dan karena data perusahaan tersebut adalah outlier, sehingga sampel akhir penelitian ini adalah 84 perusahaan, 
dengan 49 perusahaan di tahun 2010 dan 35 perusahaan di tahun 2011. Tabel 2 dalam bagian akhir naskah menyajikan hasil statistik deskriptif variabel dependen, independen dan variabel kontrol dalam penelitian ini. Dalam tabel 1 diketahui bahwa nilai mean dan median ETR, DTE, LEV dan LNAT hamper sama, sedangkan variabel dependen DCA memiliki perbedaan yang cukup signifikan. Secara umum, data terdistribusi secara normal karena outlier telah dihilangkan.

\subsection{Hasil Regresi}

Pengujian hipotesis dilakukan dengan menggunakan analisis regresi linier berganda menggunakan e-views 6. Penelitian cross-section rentan dengan masalah heteroskedastisitas. Maka, peneliti melakukan pengujian hetero dengan analisis white. Hasil pengujian menunjukkan tidak ada masalah heteroskedastisitas.

Tabel 2

Hasil Uji Regresi Pengaruh Perencanaan Pajak terhadap Manajemen Laba

\begin{tabular}{|c|c|c|c|}
\hline Variabel Independen & $\begin{array}{c}\text { Prediksi Tanda } \\
\text { Koefesien }\end{array}$ & Koefisien & Prob. t-stat \\
\hline Intersep & $?$ & 0.049583 & 0.6981 \\
\hline ETR & + & 0.282422 & $0.0053^{*}$ \\
\hline DTE & + & 1.085674 & 0.4925 \\
\hline LEV & + & 0.112592 & $0.0209 *$ \\
\hline LNAT & - & -0.006217 & 0.1657 \\
\hline $\mathrm{N}$ & 84 & & \\
\hline Prob. F-stat & $0.009539 *$ & & \\
\hline R-squared & 0.154104 & & \\
\hline Adj. R-squared & 0.111273 & & \\
\hline
\end{tabular}

*signifikan pada tingkat $5 \%$.

Dependen variabel: manajamen laba (DCA)

Sumber: data diolah dengan e-views 6 . 
Tabel 3

Prediksi Tanda Variabel

\begin{tabular}{|c|c|l|}
\hline Variabel & Prediksi & \multicolumn{1}{|c|}{ Penjelasan } \\
\hline ETR & $(+)$ & $\begin{array}{l}\text { Semakin besar nilai ETR berarti pencapaian laba yang diinginkan } \\
\text { perusahaan besar. }\end{array}$ \\
\hline DTE & $(+)$ & $\begin{array}{l}\text { Perusahaan menggunakan deferred tax expense sebagai alat untuk } \\
\text { menetapkan laba yang diharapkan. }\end{array}$ \\
\hline LEV & $(+)$ & $\begin{array}{l}\text { Perusahaan dengan tingkat leverage yang tinggi, kecil kemungkinannya } \\
\text { menggunakan income-reducing discretionary accrual karena akan memicu } \\
\text { pelanggaran debt covenant. }\end{array}$ \\
\hline LNAT & $(-)$ & $\begin{array}{l}\text { Perusahaan yang besar cenderung melakukan income-reducing } \\
\text { discretionary accrual, selain itu mereka juga memilki tax department. }\end{array}$ \\
\hline
\end{tabular}

Tabel 2 menunjukkan bahwa perencanaan pajak yang diproksikan dengan ETR berpengaruh positif dan signifikan terhadap manajemen laba. Hasil ini mendukung H1 yang berarti bahwa semakin besar nilai ETR yang dicapai perusahaan berarti pencapaian laba yang diinginkan perusahaan besar. Nilai positif membuktikan trade-off yang dihadapi oleh perusahaan, yaitu nilai laba kini yang tinggi berakibat pada tingginya pajak kini yang ditanggung perusahaan.

Hubungan antara beban pajak tangguhan dengan manajemen laba yang juga ditunjukkan dalam tabel 3 menunjukkan hasil positif namun tidak signifikan. Hasil ini bertentangan dengan hipotesis 2 dan teori menurut liability view yaitu pajak tangguhan berkontribusi negative terhadap firm value, tetapi mendukung teori menurut equity view yang menyatakan bahwa pajak tangguhan tidak memiliki nilai relevansi karena hal yang berhubungan dengan arus kas sangat tidak pasti (Chludek, 2011).

Hasil uji statistik F menghasilkan hasil yang signifikan dengan nilai $R$-squared dan adjusted $\mathrm{R}$-squared masing-masing $15,4 \%$ dan $11,1 \%$. Hal ini menunjukkan bahwa secara keseluruhan variabel independen dapat menjelaskan variabel dependen. Perencanaan pajak merupakan tindakan manajemen yang mempengaruhi besaran current accrual yang diinginkan manajemen. Tetapi di antara tarif pajak efektif dan beban pajak tangguhan terlihat bahwa yang lebih mempengaruhi tindakan diskresioner akrual kini oleh manajemen adalah tarif pajak efektif. Perbandingan ini kemungkinan dikarenakan proksi manajemen laba yang digunakan adalah current discretionary accrual yang lebih sesuai untuk item yang terkait dengan tindakan kini maanjemen (tarif pajak efektif yang dihitung dengan membagi pajak kini dengan laba sebelum pajak), sedangkan beban pajak tangguhan lebih merefleksikan tindakan manajer terhadap item laporan keuangan tahun sebelumnya. 


\section{KESIMPULAN}

Berdasarkan hasil pengujian empiris yang telah dijelaskan pada bagian sebelumnya, maka kesimpulan penelitian ini adalah:

1. Hasil pengujian empiris membuktikan bahwa perencanaan pajak yang diproksikan dengan tarif pajak efektif lebih berpengaruh signifikan dari pada perencanaan pajak yang diproksikan dengan beban pajak tangguhan.

2. Beban pajak tangguhan tidak berpengaruh signifikan terhadap manajemen laba. Hasil ini mendukung teori equity view yang menyatakan bahwa pajak tangguhan tidak memiliki nilai relevansi karena ketidakpastian hal yang berhubungan dengan arus kas.

3. Secara umum hasil penelitian menunjukkan bahwa perencanaan pajak berpengaruh terhadap besaran discretionary current accrual.

\section{REFERENSI}

Astrid, K. C. .2011. Perceived versus actual cash flow implications of deferred taxes-an analysis of value relevance and reversal under IFRS. Journal of International Accounting Research, 10(1), $1-25$.

Comprix, J., Lillian, F. M., \& Andrew, P. S. 2012. Bias in quarterly estimates of annual effective tax rate and earnings management. The Journal of the American Taxation Association, 34(1), 31-53.

Dan, S. D., Cristi, A. G., \& Lillian, F. M .2004. Last-chance earnings management: Using the tax expense to meet analysts' forecasts. Contemporary Accounting Research, 21 (2), 431459.

Djamaluddin, Subekti., Rahmawati dan Wijayanti, Handayani Tri. 2007. Analisis perubahan aktiva pajak tangguhan dan kewajiban pajak tangguhan untuk mendeteksi manajemen laba.

Guenther, D. A. 1994. Earmings management in response to corporate tax rate changes: Evidence from the 1986 tax reform act. The Accounting Review, 69(1), 230-230.

Healy, P. 1985. The effect of bonus Schemes on accounting decisions. Journal of Accounting and Economics 7 (April): 85-107.

Ikatan Akuntansi Indonesia. 2009. Exposure Draft Pernyataan Standar Akuntansi Keuangan.

Ikatan Akuntansi Indonesia. 2010. Exposure Draft Pernyataan Standar Akuntansi Keuangan.

Jang, Lesia., Sugiarto, Bambang., Siagian, Dergibson. 2007. Faktor-faktor yang mempengarubi kualitas laba pada perusabaan manufaktur di BEJ. Akuntabilitas, Vol. 6, No.2, hal. 142149.

Jensen, Michael. C., \& Meckling, William H. 1976. Theory of the firm: managerial behavior, agency costs and ownership structure. Journal of Financial Economics, V. 3, No. 4, pp. 305-360. 
Lin, Bingxuan., Lu, Rui dan Zhang, Ting. 2012. Tax-induced earnings management in emerging markets: evidence from cbina. The Journal of the American Taxation Association, 34(2), 19-44.

Martani, Dwi. 2012. Perpajakan dan Akuntansi. Slide Materi Perpajakan dan Akuntansi National Workshop in Accounting Education: Valuation, IFRS, and Taxation.

Phillips, Jhon., Pincus, Morton., \& Rego, Sonja Olhoft. 2003. Earnings management: new evidence based on deferred tax expense. The Accounting Review, Vol. 78, No. 2, pp. 491521.

Q, J. Y., \& C, S. A. C. 2004. Earnings management of profit firms and loss firms in response to tax rate reductions. Review of Accounting \& Finance, 3(1), 67-92.

Richardson, Grant dan Lanis, Roman 2007. Determinants of the variability in corporate effective tax rate and tax reform: Evidence from Australia. Journal of Accounting and Public Policy 26 (2007) 689-704. 